\title{
Topical Anti-Infective Agent
}

National Cancer Institute

\section{Source}

National Cancer Institute. Topical Anti-Infective Agent. NCI Thesaurus. Code C28394.

A natural or synthetic agent used for local application on skin, mucosa, or cavities, a

Topical Anti-Infective Agent, formulated as a sterile solution or cream, commonly

displays therapeutic or prophylactic antibiotic properties against infectious viral, bacterial, or protozoal agents by inhibiting growth and survival. ( $\mathrm{NCI04)}$ 